\title{
Changes in Achievement Motivation among University Freshmen
}

\author{
Markus Dresel $^{1} \&$ Robert Grassinger ${ }^{1}$ \\ ${ }^{1}$ Department of Psychology, University of Augsburg, Germany \\ Correspondence: Markus Dresel, Department of Psychology, University of Augsburg, Universitaetsstr. 10, 86135 \\ Augsburg, Germany. Tel: 49-821-598-2606. E-mail: markus.dresel@phil.uni-augsburg.de
}

Received: May 22, 2013 Accepted: June 11, 2013 Online Published: June 21, 2013

doi:10.11114/jets.v1i2.147

URL: http://dx.doi.org/10.11114/jets.v1i2.147

\begin{abstract}
Changes in achievement motivation over the first semester of university studies were examined with $N=229$ freshmen, who were surveyed twice in the present study. Students' academic self-concepts, achievement goals, and subjective values were chosen as theoretically central components of achievement motivation. The results indicated significant deterioration in achievement motivation over the course of the first semester of university studies, a phenomenon which affected a large proportion of the first-year students. Regression analyses provided evidence that motivation, prior to the start of university studies, and the changes in motivation had incremental validity over measures of prior school-achievement in predicting self-regulated learning, performance in examinations, as well as the intention to change university majors or drop out completely (partially in interaction with prior school-achievement).
\end{abstract}

Keywords: academic self-concept, achievement goals, subjective value, student dropout, self-regulated learning, changes in motivation

\section{Introduction}

Freshman year at college is linked to a wide variety of changes in one's life. In addition to their social environment, freshmen are confronted with changes in the achievement situations they contend with (e.g., increased levels of difficulty, higher demands pertaining to self-regulated learning, as well as a transition to a different type of social reference group in comparison with secondary school; Pillay \& Ngcobo, 2010; Schiefele, Streblow, Ermgassen \& Moschner, 2003). Against this background, one can expect to find adverse changes in achievement motivation among freshmen students and, as a consequence, in learning behavior. From a practical perspective, these expected adverse changes would indicate a need for action to support undergraduates at the start of their university studies (see Bachmann, Berta, \& Hornung, 1999). However, there are surprisingly few recent studies on this topic which are in accordance with the current understanding of achievement motivation (e.g., Moschner, 2000; see also Eccles \& Wigfield, 2002).

With the present work we pursued two main objectives: First, we aimed to provide a thorough view of changes in relevant components of achievement motivation among university freshmen. Second, we aimed to consider the significance of motivational components, and the changes occurring in them, for self-regulated learning, performance and the intention to drop out of university or switch majors.

\subsection{Achievement Motivation in University Studies}

The expectancy-value-model of achievement motivation proposed by Eccles and Wigfield (2002), as well as achievement goal theory (e.g., Elliot \& McGregor, 2001), function as theoretical frameworks of achievement motivation underlying the present investigation. Our focus is on the components of achievement motivation fundamental to these models which are seen as central predictors of achievement-related behavior (for overviews see Schunk, Pintrich \& Meece, 2007; Pintrich \& Zusho, 2007). These components are the academic self-concepts (primarily expectancy-related), the subjective values (primarily value-related), and the achievement goals (primarily value-related) freshmen hold for their chosen university majors.

An individual's academic self-concept refers to assumptions held pertaining to his or her own ability levels (Marsh \& Craven, 1997). Numerous findings have indicated that academic self-concept exerts positive influences on the range and quality of efforts undertaken in learning and subsequent performance quality (for an 
overview see Marsh \& Martin, 2011). For example, considerable evidence exists to show that the academic self-concepts of college and university students predict their persistence, performance, and college attrition (e.g., Choi, 2005; House, 1992; Valentine, DuBois, \& Cooper, 2004).

Subjective value refers to a representation of the appeal the learning activities and their results hold for an individual. The conceptualization offered by Eccles and Wigfield (2002) integrates the intrinsic value of specific learning activities, the personal significance of success for the self-definition of the learner, as well as the instrumental value placed on the usefulness of the learning activities. It has been well documented that the positive evaluation of a subject area is associated with appropriate choice behavior, extensive learning efforts, as well as an effective system of self-regulated learning (see Wigfield, Tonks \& Klauda, 2009).

Finally, achievement goals refer to the competence-based aims that individuals use to guide behavior (e.g., Elliot \& McGregor, 2001). Current models make two distinctions (for an overview see Maehr \& Zusho, 2009). The first distinction is between mastery goals and performance goals. Persons who pursue mastery goals strive to gain knowledge and develop their skills. Performance goals, on the other hand, focus on leaving other persons with a positive impression of one's skills and achievements. The second distinction concerns the positive vs. negative valence of the state represented in one's goal - here a differentiation is made between approach goals and avoidance goals. This leads to performance-approach goals and performance-avoidance goals, in other words the goal of appearing to be competent and the goal of not appearing to be incompetent (e.g., Middleton \& Midgley, 1997). Further distinctions are made between mastery-approach goals and mastery-avoidance goals, that is between a focus on goals which are directed towards the acquisition of knowledge and those which focus on the avoidance of incorrect or incomplete knowledge (Elliot \& McGregor, 2001). The central theoretical assumption here is that different achievement goals necessitate different perceptions of learning and achievement, as well as, qualitatively different cognitive processes during learning (Maehr \& Zusho, 2009). It has been well documented that mastery-approach goals are associated with extensive effort and successful self-regulated learning, while performance-avoidance goals are connected to weak attempts at effort, poor performances and experiences of test-anxiety (e.g., Ziegler, Dresel \& Stoeger, 2008). Less conclusive are findings pertaining to performance-approach goals, which correlate positively with achievement and academic self-concept but have little or no positive effect on the process of learning, as well as mastery-avoidance goals, which have not yet been extensively studied (e.g., Elliot \& McGregor, 2001; Midgley, Kaplan \& Middleton, 2001; Moller \& Elliot, 2006).

With regard to the interplay between the expectancy-related and value-related components of achievement motivation, it is assumed that academic self-concepts, subjective values, and achievement goals are separate, but nevertheless closely and reciprocally interrelated components of achievement motivation (e.g., Dresel \& Hall, 2013; Skaalvik \& Skaalvik, 2005; Wigfield \& Eccles, 1992).

\subsection{Changes in Achievement Motivation at the Start of University Studies}

Empirical findings pertaining to changes in achievement motivation at the start of university studies are rather sparse. This stands in sharp contrast to the voluminous body of research literature on changes in the achievement motivation of primary and secondary school students (for an overview see Wigfield \& Eccles, 2002). From a motivational perspective, it is highly significant that matriculation into a new course of studies is accompanied by a change of reference groups (fellow students take the place of schoolmates). The new reference group is usually characterized by an average competence level exceeding that of the prior high school reference group. Extensive research on the "big-fish-little-pond effect" have shown that a change into a reference group with a better than average achievement level is often associated with declines in academic self-concept due to the significance of external comparisons (Marsh, 1987). Consequently, we expected an average drop in academic self-concepts at the start of a course of studies at university. This trend should be exacerbated by the higher demands being placed on the student.

It should also be noted that many students hold inaccurate expectations prior to beginning a course of studies at university, for instance with respect to the content of their major or future career opportunities related to the major they chose (Chang, Cohen, Pike, Pooley, \& Breen, 2003; Heublein, Schmelzer \& Sommer, 2005). It then follows that matriculation at university is often associated with disappointment. Consequently, we expected average declines in the subjective value of a major course of studies at the start of the first semester.

However, we did not expect that the components of achievement motivation among all students would be affected in a negative manner. Rather, we expected that these effects would only exist in a proportion of the students, basically those who were not able to adapt themselves to the demands made on them by their specific academic programs. In contrast, the maintenance of, or improvement in, motivation can be considered to be an 
indicator for the successful management of the critical life event of embarking on university studies (Bachmann et al., 1999). We expected to ascertain that a substantial proportion of university freshman are successful in this manner. Nevertheless, almost nothing is known regarding inter-individual differences in motivational changes during the transition to university (see Meier, Reindl, Grassinger, Berner, \& Dresel, in press).

The very few prior studies addressing the assumptions outlined above revealed, in part, inconsistent findings. Moschner (2000) analyzed data provided by college students who responded regularly to questionnaires over the first five semesters of their college programs. The results pointed to a decrease in intrinsic motivation and an increase in extrinsic motivation. On the other hand, deterioration in academic self-concept associated with the big-fish-little-pond effect was not observable in the work of Moschner (2000). In contrast, Bachmann et al. (1999) were able to find that academic self-concepts decreased, on average, over the course of the first semester at college. Phan (2010) investigated changes in achievement goals at the start of university studies. He found that mastery-approach goals develop positively over the course of the first three years in college, but did not observe any change in performance-approach goals. A shorter surveillance period was used for the observations made by Fryer and Elliot (2007), who analyzed the changes in achievement goals in the context of introductory college courses. They addressed change on the level of differential continuity (stability of inter-individual differences), change on the level of mean values (average changes), and change on the individual level (proportions of students with significant declines, with significant increases, or with unsubstantial changes). Their results regarding change on the mean level indicated, in contrast to the findings of Phan (2010), that over the time span of a course, it is predominantly mastery-approach goals which drop in significance, while performance-avoidance goals seem to gain in significance. Fryer and Elliot (2007) also found evidence for substantial differences between undergraduate students, as expressed in substantial proportions of students with deterioration in achievement goals and, at the same time, considerable proportions of students with improvement in achievement goals (see also Muis \& Edwards, 2009).

\subsection{Significance of Achievement Motivation in University Learning}

A series of studies on the prognosis of academic success in higher education (based on indicators which were assessed prior to the start of the university program) provide evidence that achievement motivation is associated with learning behavior as well as performance above and beyond prior achievement (e.g., Gold \& Souvignier, 2005; Ning \& Downing, 2010; Olani, 2010; Robbins et al., 2004; Schiefele et al., 2003). For instance the results of Schiefele et al. (2003) indicated that exam performance and self-regulated learning behavior (effort and the application of meta-cognitive strategies) at the end of introductory phases of university programs depend on subjective value as well as academic self-concept.

Prior studies also suggest that motivational factors play a significant role in the context of student drop-out. With a longitudinal study Schiefele, Streblow and Brinkmann (2007) were able to show that students who ended their university programs prematurely differed already, at the start of undergraduate studies, from classmates who continued in their programs, in the form of detrimental values on various components of achievement motivation (see also Gold \& Kloft, 1991).

Thus, the present state of findings underpins the significance of achievement motivation in higher education. Nevertheless, it shows a need for augmentation, in that little consideration has been accorded to changes in motivational components over the course of university studies and the focus was instead on achievement motivation at a particular point in time (mostly prior to the start of university studies). Presumably, not only achievement motivation at a certain point in time may explain learning behavior and achievement, but also the temporal changes in achievement motivation. From a methodological point of view, information regarding motivational change comprises more information than a single measure, and this supplemental information is likely to increase the explained criterion variance. Moreover, from a conceptual point of view, it can be assumed that individuals hold representations of the temporal changes in their achievement motivation, resulting from intra-individual comparisons of their motivational states at different points of time. For example, a freshman may hold the view that she initially had an unrealistic view of her course of studies and that she is now disappointed about its low practical relevance. Another freshman may experience a growth in self-doubt concerning his capabilities to master the demands of his course of studies in contrast to his initially strong confidence in his abilities. Such cognitive representations regarding temporal changes in one's own achievement motivation may have emotional concomitants and may influence learning behavior and academic achievement above and beyond achievement motivation at a particular point in time (see Fischer and Rustemeyer, 2007). To the best of our knowledge, no prior theoretical or empirical work has focused on the relevance of motivational change in the context of the transition to higher education. 


\subsection{Research Questions}

As demonstrated in the literature review, very little prior research has addressed change in achievement motivation during the transition to university, particularly in accordance with the current understanding of achievement motivation or using different perspectives on change (as utilized within specific courses by Fryer \& Elliot, 2007). Thus, the overriding aim of the present work focuses on changes in the academic self-concept, the subjective value, and the achievement goals of university freshmen. Specifically, we addressed two main research questions:

(1) Which average and individual changes in the above named components of first-year university students' achievement motivation occur over the course of their first semester in their chosen programs?

(2) Which relevance have first-year university students' achievement motivation and its temporal change for their learning behavior, their success on examinations, and their tendency to drop out or switch majors?

As mentioned in more detail above, we expected considerable change in achievement motivation. Moreover, we expected that not only achievement motivation at the start of university studies and, potentially, its interaction with prior achievement would predict these outcomes, but also the temporal change in achievement motivation over the course of the first semester (as argued above).

\section{Method}

\subsection{Procedure and Sample}

We implemented a study with two measuring points over the course of the first semester of university studies (T1: Prior to the start of the first semester; T2: At the end of the first semester). At the first measuring point all students newly matriculated in non-medical courses of study at a medium-sized German university, renowned for its programs in mathematics and the natural sciences, were contacted by mail and requested to complete an online questionnaire. To expand the sample, newly enrolled students were additionally asked to complete a paper version of the questionnaire in the context of a student-organized orientation event as well as in the first session of introductory courses if they had not completed the online questionnaire. A total of 442 first year students participated at the first measuring point (28\% via the online version). This corresponds to $59 \%$ of the persons contacted. At the second measuring point, during the final two weeks of the lecture period, students were asked to complete a second questionnaire in the context of their normal classes (in paper format only). A total of 450 students completed these questionnaires.

With the aid of a coding system, data for $N=229$ of the students could be accounted for at both measuring points (this corresponds to $52 \%$ of the individuals queried at the first measuring point). These constitute the sample examined in the present analysis. The highest proportion of students, those pursuing majors in the field of mathematics, comprised about one third (32\%) of the sample, this was followed by those majoring in the natural sciences $(26 \%)$, technological courses $(26 \%)$, economics $(14 \%)$ and others $(2 \%)$. The mean age of the participants at the first measuring point came to 20.6 years $(s=1.4)$, the proportion of women in the study was $39 \%$.

\subsection{Measuring Instruments}

We measured three central components of students' achievement motivation (academic self-concept, subjective value, and achievement goals), two facets of their self-regulated learning (effort regulation and meta-cognitive strategies), their prior school-achievement and exam performance, as well as students' intentions to terminate studies or switch majors. Unless otherwise noted, the items used were to be answered along a six-point response scale ranging from 1 (absolutely false) to 6 (absolutely true). All measurements were coded so that a higher value reflects a stronger expression of the construct. Internal consistencies for all measurements are reported in Table 1.

\subsubsection{Achievement Motivation}

The academic self-concept specific to the field of study was assessed with three item pairs adapted from the scale "Confidence in one's own intelligence" (Dweck, 1999). The item pairs each contained one statement pertaining to a high and one to a low self-assessment, which were presented as the two poles along a six point answer scale (sample item pair: "I feel pretty confident about my intellectual abilities, which I need in my field of studies" and "I'm not very confident about my intellectual abilities, which I need in my field of studies").

In assessing the subjective value of a course of studies, three items developed by Ziegler, Dresel, Stoeger and Schober (2005) were adapted. Three significant value components were assessed, in accord with conceptualizations advanced by Eccles and Wigfield (2002), with one item each: Intrinsic value ("My course of 
studies is a lot of fun for me"), attainment value ("It is very important to me to achieve well in my course of studies"), and instrumental value ("The things that I learn in my course of studies are very useful").

In order to assess achievement goals, a questionnaire developed by Elliott and McGregor (2001) was translated into German and adapted to the context of university studies. This version contained scales assessing mastery-approach goals ("In my field of study I want to learn as much as possible"), mastery-avoidance goals ("In my field of study I am sometimes afraid that I may not understand the content as thoroughly as I'd like"), performance-approach goals ("In my field of study it is important to me to do better than other students"), and performance-avoidance goals ("In my field of study I just want to avoid doing poorly"). Each scale consisted of three items.

Table 1. Descriptive statistics

\begin{tabular}{|c|c|c|c|c|c|c|c|}
\hline \multirow[b]{2}{*}{ Variable } & \multirow[b]{2}{*}{$\mathrm{T}$} & \multirow[b]{2}{*}{$M$} & \multirow[b]{2}{*}{$s$} & \multirow[b]{2}{*}{$\alpha$} & \multicolumn{2}{|c|}{ Range } & \multirow[b]{2}{*}{ Skew } \\
\hline & & & & & Potential & Actual & \\
\hline \multicolumn{8}{|c|}{ Achievement motivation } \\
\hline \multirow[t]{2}{*}{ Academic self-concept } & $\mathrm{T} 1$ & 4.49 & 0.81 & .83 & $1-6$ & $1.7-6.0$ & -0.75 \\
\hline & $\mathrm{T} 2$ & 4.09 & 1.02 & .88 & $1-6$ & $1.0-6.0$ & -0.44 \\
\hline \multirow[t]{2}{*}{ Subjective value } & $\mathrm{T} 1$ & 4.91 & 0.57 & .67 & $1-6$ & $3.0-6.0$ & -0.23 \\
\hline & $\mathrm{T} 2$ & 4.43 & 0.74 & .65 & $1-6$ & $2.0-6.0$ & -0.53 \\
\hline \multirow[t]{2}{*}{ Mastery-approach goals } & $\mathrm{T} 1$ & 4.78 & 0.73 & .75 & $1-6$ & $2.0-6.0$ & -0.86 \\
\hline & $\mathrm{T} 2$ & 4.22 & 0.81 & .75 & $1-6$ & $1.0-6.0$ & -0.40 \\
\hline \multirow[t]{2}{*}{ Mastery-avoidance goals } & $\mathrm{T} 1$ & 4.15 & 0.85 & .75 & $1-6$ & $1.7-6.0$ & -0.27 \\
\hline & $\mathrm{T} 2$ & 4.13 & 0.85 & .78 & $1-6$ & $1.0-6.0$ & -0.50 \\
\hline \multirow[t]{2}{*}{ Performance-approach goals } & $\mathrm{T} 1$ & 3.51 & 1.10 & .91 & $1-6$ & $1.0-6.0$ & 0.14 \\
\hline & $\mathrm{T} 2$ & 3.10 & 1.11 & .92 & $1-6$ & $1.0-6.0$ & 0.17 \\
\hline \multirow[t]{2}{*}{ Performance-avoidance goals } & $\mathrm{T} 1$ & 4.05 & 0.85 & .61 & $1-6$ & $1.0-6.0$ & -0.28 \\
\hline & $\mathrm{T} 2$ & 3.98 & 0.83 & .61 & $1-6$ & $1.0-6.0$ & -0.16 \\
\hline \multicolumn{8}{|c|}{ Self-regulated learning } \\
\hline Effort regulation & $\mathrm{T} 2$ & 3.85 & 0.77 & .83 & $1-6$ & $1.3-6.0$ & -0.25 \\
\hline Meta-cognitive strategies & $\mathrm{T} 2$ & 3.95 & 0.74 & .89 & $1-6$ & $1.0-5.9$ & -0.50 \\
\hline \multicolumn{8}{|c|}{ Prior school-achievement and exam performance } \\
\hline Prior school-achievement & $\mathrm{T} 1$ & 2.09 & 0.57 & .87 & $1-6$ & $1.0-3.4$ & 0.27 \\
\hline Number of exams attempted & $\mathrm{T} 2$ & 1.15 & 0.92 & - & $\geq 0$ & $0-4$ & 0.55 \\
\hline Number of exams passed & $\mathrm{T} 2$ & 0.70 & 0.81 & - & $\geq 0$ & $0-3$ & 0.74 \\
\hline \multicolumn{8}{|c|}{ Intention to terminate studies or switch majors } \\
\hline $\begin{array}{l}\text { Intention to terminate studies } \\
\text { or switch majors }\end{array}$ & $\mathrm{T} 2$ & 2.59 & 1.10 & .91 & $1-6$ & $1.0-6.0$ & 0.75 \\
\hline
\end{tabular}

Note. $N=229 . \mathrm{T}=$ Measuring point. $\mathrm{T} 1=$ Prior to the start of the first semester. $\mathrm{T} 2=$ End of the first semester.

\subsubsection{Self-regulated Learning}

Using the six item scale effort regulation at the end of the first semester, we assessed the extent of learning effort which had been made as well as how successfully the students adapted to the increased demands associated with their new learning material ("When I am studying I work as long as I have to, until I am sure that I will be able to produce good results"). The scale constitutes an abridged version of a scale conceptualized by Ziegler et al. (2005).

In order to assess meta-cognitive strategies, a scale applied at the second measuring point appraised the scope 
and range of the implementation of planning prior to learning, monitoring during learning, and evaluation after learning. To this end, 11 items were adapted from an existing instrument (Baumert, Heyn \& Köller, 1992). One sample item reads "When I study, I first take time to consider the best way to approach the material".

\subsubsection{Prior School-achievement and Exam Performance}

In the questionnaires used at the first measuring point, participants were asked to supply the grades they obtained on their final secondary-school examinations (German "Abitur") as to secure an indicator of prior school-achievement. The grades, which range in Germany from 1 (very good) to 6 (dissatisfactory), were recoded for all analyses.

As an indicator of exam performance in university studies, at the second measuring point the participants were asked to indicate the number of course exams they had passed so far. For the sake of relativisation, they were also asked to indicate the number of course exams they had participated in.

\subsubsection{Intentions to Terminate University Studies or Switch Majors}

At the second measuring point, data were collected to determine how strong an intention the student had to either change majors or drop out of university studies completely. To this end a five item scale was developed ("I often think about changing my course of studies or dropping out of college"). The complete scale is available in the Appendix.

\subsection{Potential Method Effects and Item Non-response}

Regarding a potential method effect of the online vs. paper-and-pencil questionnaires, we performed a multivariate analysis of variance with the mode of inquiry as a factor and all measures as dependent variables. This analysis revealed no significant method effect (Wilks $\lambda=.901$; multivariate $F(18,210)=1.280 ; p=.20$ ). With regard to item non-response it was found that the rate of occurrence for missing values on the item level was rather low (no item showed a rate of missing values exceeding 5\%). These were replaced by applying the expectation-maximization algorithm (see Peugh \& Enders, 2004).

\section{Results}

Descriptive statistics for all measures can be found in Table 1.

\subsection{Changes in Achievement Motivation}

Changes in achievement motivation were analyzed from different perspectives (similar to Fryer \& Elliot, 2007; see also Muis \& Edwards, 2009). The relative stability of differences among the individual students was observed on the level of differential continuity, on the level of mean values the focus was on the averages of the changes observed, and on the individual level the proportions of freshman students with strong declines, strong increases and unsubstantial changes were identified (Table 2).

In order to determine the differential continuity, correlations between values obtained at the two measuring points were calculated. These indexed a moderate to high level of stability of inter-individual differences among the students for all six motivational components. Attenuation-corrected correlation coefficients, which were calculated against the background of somewhat varying internal consistencies in the measuring instruments, indicated that differential continuity was particularly high for the subjective value and performance-avoidance goals.

In order to analyze the mean changes over the course of the first semester in university studies, a single factorial, multivariate variance analysis with repeated measurements was conducted under the consideration of all six motivational components. This revealed a robust and highly significant change in achievement motivation (Wilks $\lambda=.544$; multivariate $F(6,223)=31.210 ; p<.001 ; \eta^{2}=.456$ ). Subsequent $t$-tests indicated highly significant, moderate to large decreases in four of the six motivational components (see Table 2). It was only with regard to the two avoidance components of achievement goals that statistically significant changes could not be confirmed. Particularly strong decreases were evident for both subjective value and mastery-approach goals.

To obtain information on individual changes, for each specific motivational component we specified the percentage of students who expressed a substantial decrease, a substantial increase or did not demonstrate a substantial change. Based on Cohen's (1988) convention for interpreting effect sizes, we classified standardized individual changes as substantial when they were at least of a moderate size, i.e. when they demonstrated absolute values of $d^{\prime}=0.50$ or higher (see Table 2). With regard to academic self-concept, the analysis showed a decline for about one half of the students. About $40 \%$ of the new students were able to generally maintain their ability self-assessments, and that a small group of students actually assessed their abilities at substantially higher 
levels at the end of the semester than they did before the start of the semester. Similar distributions were also observed for the approach components of both mastery goals and performance goals. A different picture emerged for the subjective valuing of one's major course of studies. Here, we observed a substantially weaker valuing for the majority of the students (more than two thirds) at the end of the first semester in comparison to the pre-matriculation survey. As stated above, we did not find any significant differences for the avoidance components of mastery goals and performance goals on the average level. However, the analysis of individual changes revealed that this did not mean that changes only occurred among a small proportion of the new students. Actually, this applies only to about half of the students. At the end of the semester about one quarter of the new students pursued substantially more avoidance goals, and one quarter pursued substantially less avoidance goals, than they did before the start of the semester.

Table 2. Differential continuity, change on the mean level and change on the individual level for six components of achievement motivation

\begin{tabular}{|c|c|c|c|c|c|c|c|c|}
\hline & \multicolumn{2}{|c|}{$\begin{array}{l}\text { Differential } \\
\text { stability }^{\mathrm{a}}\end{array}$} & \multicolumn{3}{|c|}{$\begin{array}{l}\text { Changes on the } \\
\text { mean level }\end{array}$} & \multicolumn{3}{|c|}{$\begin{array}{l}\text { Changes on the } \\
\text { individual level }^{c}\end{array}$} \\
\hline & $R$ & $r^{*}$ & $M_{\mathrm{T} 2}-M_{\mathrm{T} 1}$ & $t$ & $d^{\prime}$ & $\%$ Decr & $\% \operatorname{Simi}$ & $\%$ Incr \\
\hline Academic self-concept & .52 & .60 & -0.40 & $6.612 *$ & -0.51 & 42.8 & 43.2 & 14.0 \\
\hline Subjective value & .51 & .77 & -0.48 & $10.972 *$ & -0.86 & 67.2 & 15.3 & 17.5 \\
\hline Mastery-approach goals & .48 & .64 & -0.56 & $10.821^{*}$ & -0.75 & 53.7 & 38.9 & 7.4 \\
\hline Mastery-avoidance goals & .44 & .57 & -0.01 & 0.246 & -0.02 & 27.5 & 47.6 & 24.9 \\
\hline Performance-approach goals & .59 & .65 & -0.40 & $6.115^{*}$ & -0.41 & 45.9 & 34.9 & 19.2 \\
\hline Performance-avoidance goals & .53 & .87 & -0.06 & 1.184 & -0.08 & 29.7 & 48.9 & 21.4 \\
\hline
\end{tabular}

Note. $N=229 . \mathrm{T} 1=$ Prior to the start of the first semester. $\mathrm{T} 2=$ End of the first semester. ${ }^{\text {a }}$ Bivariate correlations $r$ between T1 and T2 (all $p<.05$ ) and attenuation-corrected correlations $r^{*} .{ }^{\mathrm{b}}$ Results from $t$-Tests for paired samples ( $\alpha$-adjustment for 6 tests) as well as standardized individual changes (effect sizes). $d^{\prime}=\left(M_{T 2}-M_{T 1}\right) / s_{1} \cdot \sqrt{2 \cdot(1-r)}$. ${ }^{c} \%$ Decr $=$ Percentage of students with a decrease of $d^{\prime}=-0.50$ or more. \% Incr $=$ Percentage with an analogue increase. \% Simi $=$ Percentage of other students, i.e. with similar values at both measuring points. ${ }^{*} p<.05$.

For the four motivational components, for which the research literature regarding their consequences is unambiguous (academic self-concept, mastery-approach goals, performance-avoidance goals, subjective value), the proportions of first year students for whom deteriorations in more than one of these components surfaced were calculated. Deterioration in this context refers to shifts to more maladaptive manifestations, i.e. to a decrease in academic self-concept, a decrease in mastery-approach goals, an increase in performance-avoidance goals, and a decrease in subjective value. Substantial deterioration in at least three of these components was observed among $27.9 \%$ of these students (in all four: $3.9 \%$ ). Similarly, $33.6 \%$ of the students demonstrated substantial deterioration in at most one motivational component (in none: 13.1\%).

\subsection{Significance of Achievement Motivation}

In order to analyse the significance of achievement motivation prior to embarking on undergraduate studies and the significance of the changes in achievement motivation which develop later, we conducted hierarchical regression analyses (Table 3). Both of the facets of self-regulated learning, the number of examinations passed, and the intention to either drop out of university studies or switch majors were inserted as dependent variables in separate analyses. Predictors were specified block-wise. Block 1 encompassed control variables (prior school-achievement, total number of exams attempted for exam performance). Block 2 contained the six components of achievement motivation prior to the start of the university program. Due to ambivalent findings in the literature, two-sided hypotheses were examined for mastery-avoidance goals and performance-approach goals here and in the following (see Elliot \& McGregor 2001). To additionally explore possible interaction effects between entry motivation and prior achievement (e.g., the buffering effects of a favorable achievement motivation against the unfavorable consequences of low prior achievement), in Block 3 six product terms were specified which were formed by multiplying prior school-achievement with the six motivational components (Aiken \& West, 1991). Finally, in order to analyze the impacts of changes in achievement motivation over the 
course of the first semester, Block 4 consisted of one change score for each of the six motivational components. To represent change, we used the residuals from the auto-regression of the pertinent $\mathrm{T} 2$ variable on the pertinent $\mathrm{T} 1$ variable.

Table 3. Regression of effort regulation, the use of meta-cognitive strategies, exam performance and the intention to terminate studies or switch majors on achievement motivation at the start of university studies (T1) and change in achievement motivation $(\mathrm{T} 1 \rightarrow \mathrm{T} 2)$

\begin{tabular}{|c|c|c|c|c|c|c|c|c|}
\hline \multirow[b]{3}{*}{ Predictor } & \multicolumn{8}{|c|}{ Dependent variable $\mathrm{T} 2$} \\
\hline & \multicolumn{2}{|c|}{$\begin{array}{l}\text { Effort } \\
\text { regulation }\end{array}$} & \multicolumn{2}{|c|}{$\begin{array}{l}\text { Meta- } \\
\text { cognitive } \\
\text { strategies }\end{array}$} & \multicolumn{2}{|c|}{$\begin{array}{c}\text { Number of } \\
\text { examinations } \\
\text { passed }\end{array}$} & \multicolumn{2}{|c|}{$\begin{array}{c}\text { Intention to } \\
\text { terminate } \\
\text { studies or } \\
\text { switch } \\
\text { majors }\end{array}$} \\
\hline & $\Delta R^{2}$ & $\bar{B}$ & $\Delta R^{2}$ & $\bar{B}$ & $\Delta R^{2}$ & $\bar{B}$ & $\overline{\Delta R^{2}}$ & $\bar{B}$ \\
\hline Block 1: Control variables & .02 & & .00 & & $.57 *$ & & .00 & \\
\hline Prior school-achievement & & .11 & & .01 & & $.32 *$ & & .04 \\
\hline Number of examinations attempted $\mathrm{T} 2$ & & - & & - & & $.70 *$ & & - \\
\hline Block 2: Motivation T1 & $.24 *$ & & $.11^{*}$ & & .00 & & $.19^{*}$ & \\
\hline Academic self-concept & & -.06 & & $-.29 *$ & & -.01 & & $-.27 *$ \\
\hline Subjective value & & -.03 & & $.19 *$ & & -.03 & & $-.21 *$ \\
\hline Mastery-approach goals & & $.49 *$ & & .09 & & .01 & & .12 \\
\hline Mastery-avoidance goals & & -.12 & & .04 & & .00 & & -.07 \\
\hline Performance-approach goals & & .10 & & .03 & & -.04 & & -.01 \\
\hline Performance-avoidance goals & & -.03 & & .09 & & -.03 & & .07 \\
\hline $\begin{array}{l}\text { Block 3: Interaction motivation T1 x prior } \\
\text { school-achievement }\end{array}$ & .02 & & $.09 *$ & & .02 & & .03 & \\
\hline Academic self-concept & & .07 & & .06 & & -.02 & & .03 \\
\hline Subjective value & & .02 & & .09 & & .01 & & -.01 \\
\hline Mastery-approach goals & & .00 & & $-.37 *$ & & -.10 & & -.08 \\
\hline Mastery-avoidance goals & & .08 & & .00 & & $.12 *$ & & -.07 \\
\hline Performance-approach goals & & -.02 & & -.04 & & .06 & & -.03 \\
\hline Performance-avoidance goals & & .11 & & .04 & & -.07 & & .02 \\
\hline Block 4: Change in motivation $\mathrm{T} 1 \rightarrow \mathrm{T} 2^{\mathrm{a}}$ & $.13^{*}$ & & $.07 *$ & & $.05^{*}$ & & $.38^{*}$ & \\
\hline Academic self-concept & & $.13^{*}$ & & -.09 & & $.10^{*}$ & & $-.44 *$ \\
\hline Subjective value & & .10 & & $.16^{*}$ & & .05 & & $-.26 *$ \\
\hline Mastery-approach goals & & $.27 *$ & & .07 & & -.04 & & .02 \\
\hline Mastery-avoidance goals & & .04 & & $.15^{*}$ & & $-.10 *$ & & .03 \\
\hline Performance-approach goals & & -.08 & & $.16^{*}$ & & -.03 & & -.06 \\
\hline Performance-avoidance goals & & .04 & & -.06 & & $-.11 *$ & & -.10 \\
\hline Total $R^{2}$ & $.40^{*}$ & & $.28^{*}$ & & $.65^{*}$ & & $.56^{*}$ & \\
\hline
\end{tabular}

Note. $N=229 . \mathrm{T} 1=$ Prior to the start of the first semester. T2 $=$ End of the first semester. Presented are non-standardized regression coefficients of the final model. Since standardized regression coefficients can no longer be interpreted after the inclusion of product terms, all variables were $\mathrm{z}$-standardized prior to analysis. As a consequence, the non-standardized regression coefficients may be interpreted as standardized coefficients (Aiken \& West, 1991). ${ }^{a}$ Residualized change values (residuals from the auto-regression of the T2 variables on the corresponding T1 variables). ${ }^{*} p<.05$. 


\subsubsection{Effects of Prior Achievement Motivation}

Both of the facets of self-regulated learning and the intention to either drop out of university studies or switch majors at the end of the first semester could be predicted by achievement motivation prior to the start of the university program above and beyond prior school-achievement (see Table 3, Block 2). However, this was not the case for students' exam performances.

We observed that students with strong mastery-approach goals prior to the start of university studies demonstrated more effort-regulation at the end of the first semester. With respect to the use of meta-cognitive strategies at T2, a positive effect of the subjective value the students attributed to their course of studies was evident. Additionally, the results indicated a negative effect of academic self-concept on the use of meta-cognitive strategies. Further the results indicated that the better students considered their abilities to have been before the start of the first semester, and the higher the value they had attached to their course of studies at this earlier point, the less they intended to terminate their studies or switch their majors at the end of the first semester.

\subsubsection{Effects of Prior Achievement Motivation Moderated by Prior School-achievement}

An examination of potential interaction effects between entry motivation and prior achievement indicated an interaction effect of prior school-achievement and mastery-approach goals on the use of meta-cognitive strategies (see Table 3, Block 3). To enlighten this interaction effect, we calculated simple slopes (see Aiken \& West, 1991) for good, average and poor prior school-achievements $(M-s, M$ and $M+s)$, which are displayed in Figure 1. Students' mastery-approach goals had varying effects on the application of meta-cognitive control strategies, depending on prior achievement. For freshmen with poor prior achievement, pursuing more mastery-approach goals was associated with more meta-cognitive strategies $(B=0.46 ; S E=0.11 ; t=4.084 ; p$ $<.001)$. In contrast, freshmen with good prior achievement used less meta-cognitive strategies when pursuing more mastery-approach goals $(B=-0.28 ; S E=0.11 ; t=2.470 ; p<.05)$. For students with average prior achievement, no effect of mastery-approach goals on meta-cognitive strategies was evident $(B=0.09 ; S E=0.08$; $t=1.232 ; p=.22$ ).

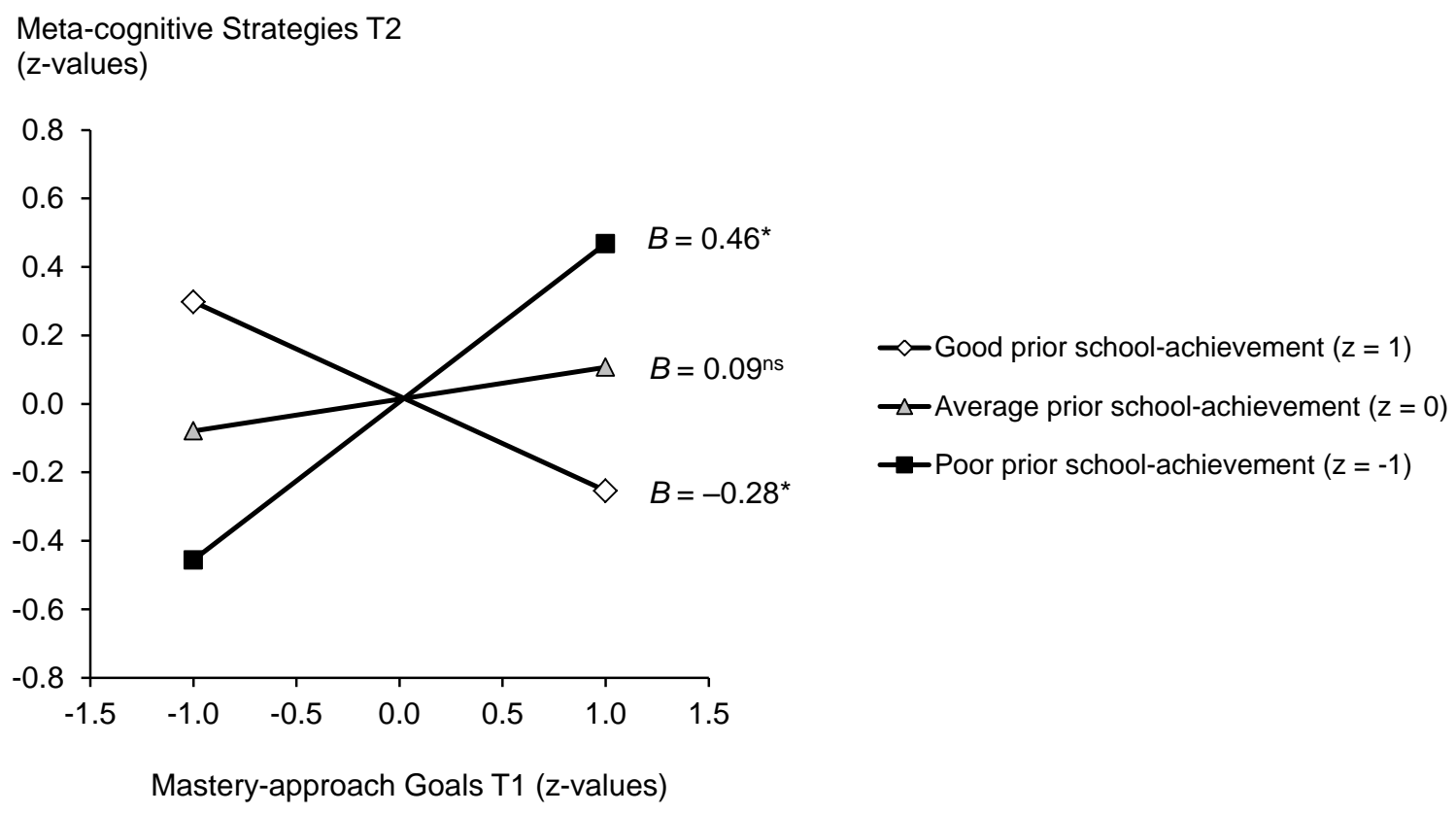

Figure 1. Interaction effect of mastery approach goals and prior school-achievement on the use of meta-cognitive strategies $\left(* p<.05 ;{ }^{\text {ns }}\right.$ not significant $)$

No other robust interaction effect between prior achievement motivation and prior school-achievement was observed for any of the four dependent variables. For the number of examinations passed, the analysis revealed a significant regression coefficient for the interaction term between prior mastery-avoidance goals and prior 
school-achievement (see Table 3). However, this interaction effect did not turn out to be robust since the proportion of explained variance did not increase significantly. Moreover, simple slope analysis indicated similar regression coefficients for good, average, and poor prior school-achievements, which did not differ significantly from nil in any of the cases.

\subsubsection{Effects of Change in Achievement Motivation}

All four indicators of student learning behavior, success on examinations, and the tendency to drop out or switch majors could be predicted from changes in achievement motivation over the course of the first semester (see Table 3, Block 4). The stronger undergraduates' self-concepts and mastery-approach goals decreased over the course of the first semester, the less advantageous was the regulation of learning efforts at the end of the first semester. Moreover, university freshmen were less likely to use metacognitive strategies at the end of the first semester, the more their subjective valuing of their courses of studies, their mastery-avoidance goals, and their performance-approach goals a decreased. With regard to exam performance, analyses indicated that students performed better, the better they were at maintaining, or increasing, their academic self-concepts and the more their mastery-avoidance and performance-avoidance goals decreased. Finally, freshmen's intention to terminate or switch their course of studies was stronger, the more their academic self-concepts and their subjective valuing of the course of studies decreased over the course of the first semester.

\section{Discussion}

The aim of the present paper was to analyze changes in achievement motivation among university students over the transitional period experienced at the start of their studies. The research literature on this topic is rather sparse. Specifically, we focused on three types of change, namely differential continuity, mean level change, and change on the individual level (research question 1). This comprehensive perspective on different types of change offers a deep understanding of alterations in undergraduate achievement motivation and contributes novel and meaningful findings to the research literature since, up to now, it has been largely absent in the field (except for the course-specific results presented by Fryer \& Elliot, 2007). Additionally, we examined the relevance of achievement motivation and its temporal change for learning behavior, success on examinations, and the tendency to drop out or switch majors above and beyond the relevance of prior achievement (research question 2). Although a series of studies proving the effects of achievement motivation prior to entering university on different outcomes already exist (e.g., Robbins et al., 2004), predicting these outcomes from temporal changes in achievement motivation is novel. We presented methodological and conceptual rationales for presuming that temporal changes in achievement motivation may influence behavior and performance.

Our findings regarding our first research question indicated that, on average, achievement motivation deteriorates sharply over the first semester of university studies. This deterioration, which can be referred to as a "motivational slump" primarily affected those motivational components for which adaptive consequences are unambiguously documented in the literature, namely self-concept, mastery-approach goals and the subjective value of one's course of studies (Maehr \& Zusho, 2009; Marsh \& Martin, 2011; Wigfield et al., 2009). The avoidance component of performance goals, which is clearly associated with maladaptive consequences, however, remained constant on average. A consideration of the individual changes demonstrated that not all students are affected by substantial declines of this nature but rather, depending on the motivational component, between $40 \%$ and $70 \%$ of new university students.

One could suspect that the maladaptive changes in achievement motivation observed for the majority of university freshman are an effect of changing reference groups and disappointment regarding prior expectations (e.g., Chang et al., 2003). Additionally, increased levels of difficulty and higher demands, compared to secondary school, should be mentioned as a possible contextual antecedent of maladaptive shifts in achievement motivation.

Maladaptive shifts in achievement motivation pertaining to university studies had already been detected by Moschner (2000). Beyond a decrease in subjective valuing, the current findings also point to considerable declines in the self-concepts and mastery-approach goals of the undergraduate students. These conform to findings reported by Bachmann et al. (1999) and the predictions drawn from the literature on the big-fish-little-pond effect (Marsh, 1987). In contrast to prior and current findings indicating maladaptive developments at the beginning of university studies, Phan (2010) found evidence for positive development in pursuing mastery (approach) goals over the period of three years of university studies. These seemingly contradicting findings could be a result of varying time spans in the different investigations. It may well be the case that a majority of university freshmen experience a remarkable decrease in motivation in their first one or two semesters, but recover afterwards with increasing adaptation to the context of higher education (in cases 
where they do not drop out from university studies).

Our results regarding the relevance of initial achievement motivation for learning behavior in university studies, examination performance and the intention to terminate a course of studies complement previous findings (Gold \& Souvignier, 2005; Robbins et al., 2004) by addressing expectancy and value aspects of achievement motivation simultaneously, and by focusing on motivational change itself as an antecedent of cognition and behavior (research question 2). Consistent with previous findings, pursuing mastery-approach goals as well as the subjective value of a course of studies were significant predictors of an adaptive, self-regulatory learning behavior (for an overview see Schunk et al., 2007). The negative effect of self-concept on the use of meta-cognitive strategies has already been disclosed in earlier studies, and can, presumably, be attributed to the circumstance that fewer difficulties which command a (deliberate) regulation occur, or are perceived, when positive convictions concerning own abilities are dominant (see Dresel \& Haugwitz, 2005). Our findings underscore that both, the self-concept in the field of study as well as the subjective value of the course of studies prior to matriculation were powerful explanatory factors with regard to the intention to terminate one's course of studies or switch majors. Consequently, these two motivational components should not be considered in isolation from one another, for instance when counseling students in danger of terminating their academic careers.

In addition to the non-moderated effects, an influence of achievement motivation prior to the start of universities was evident which was dependent on prior achievement. The expected positive effect of mastery-approach goals on meta-cognitive strategies was evident only among students with detrimental prior school-achievements. This may be explained by a tendency among these students who may initiate a particularly intense form of self-regulated learning in order to compensate for perceived deficits in prior achievements. However, among students with above-average prior school-achievements, a negative effect of mastery-approach goals on meta-cognitive strategies use was obvious. Building on the above mentioned assumption that students with good prior achievement experience less difficulties and are, consequently, less inclined to adapt their learning activities, it can be speculated that pursuing strong mastery-approach goals promotes learning processes which are characterized by a large momentum and even experiences of flow (e.g., Engeser \& Rheinberg, 2008). Meta-cognitive control may be executed automatically, remain unconscious, and may not be accessible via our measure of conscious strategy use. Clearly, future research is needed to further enlighten this interaction effect.

Controlling for prior school-achievement and prior achievement motivation, individual changes in several components of achievement motivation had a high impact on self-regulated learning, exam performance and the intention to terminate or change course of studies at the end of the first semester. This was particularly noticeable with regard to the intention to terminate university studies or switch majors, whereby (analogous to the effects of motivation prior to the start of university studies) both growing doubt in one's own abilities as well as increasingly detrimental assessments of the value of the course of studies being pursued were highly predictive. Furthermore, academic learning behavior and examination performance were more positive at the end of the first semester when the average motivational slump following the start of university studies was mitigated, or did not occur at all. At this point it is worth noting that different aspects of self-regulated learning (effort regulation, use of meta-cognitive strategies) depended on changes in different components of achievement motivation. This may be due to the fact that different aspects of self-regulated learning may be indicated in the face of different demands (e.g., meta-cognitive control primarily for complex or voluminous learning tasks).

An interesting and relevant task for future research concerns the open question of whether these results regarding the relevance of motivational change can be attributed to the richer information that is represented by change scores (methodological interpretation) or to subjective representations of temporal changes in one's own achievement motivation (substantial interpretation). Against the background of a social-constructivist view on motivation, it seems well advised to (additionally) measure perceived motivational change in future work instead of only inferring it from two or more measures of the given motivation at certain points in time. Accordingly, one contribution of the present paper could be the encouragement of more research addressing the relevance of cognitive representations of (motivational) change.

Of course, the present study has some limitations. The most important limitation is that the present study only encompassed two measuring points within one semester. Therefore, conclusions could be drawn only with respect to changes within a relatively short time span. It is, however, important to know how the motivation of university freshmen immediately responds after taking up a course of studies, i.e. in the context of the transition to higher education (see Meier et al., in press). From a methodological point of view, it has to be noted that due to the limited number of measuring points it was not possible to apply modern approaches to model longitudinal data (e.g., latent growth curve modeling) which allow, for example, for the separation of true variance and error variance in motivational change (see Phan, 2010). A further limitation on the present study concerns the 
operationalization of study drop-out, which confounded several aspects. Future research should separately consider the termination of a course of studies and changing from one course of studies to another, and should analyze not only the intention but also the actual implementation of either of these two far-reaching decisions (see Heublein et al., 2005; Schiefele et al., 2007). Nonetheless, the consideration of mental activities focused on the termination or switch of majors can be understood as an early warning signal. They could also take on a great deal of significance when providing counseling and student advisory services. Furthermore, when interpreting the results one should hold in mind that some of the measures were somewhat low in reliability even though well-known instruments were used. Finally, it should be noted that the students assessed in the study were all attending the same university (one which is, however, typical for universities with a high profile in mathematics and the natural sciences) and that participation in the study was unsolicited with a 59\% initial response rate and a $52 \%$ response rate at the second measuring point. Thus, the representativeness of the sample for the population of all university freshmen is questionable.

Our findings, nevertheless, supplement the existing literature by illuminating that achievement motivation among undergraduate students frequently deteriorates in a quite dramatic manner over the course of the first semester, and that motivational changes can be of, in part strong, relevance for learning behavior, success on examinations and the tendency to drop out or switch majors.

From a practical perspective, our findings indicate an evident need for action to support achievement motivation at the start of university studies (see Bachmann et al., 1999). Apparently it is not a small group, but rather a majority, of incoming students, who are at risk of experiencing massive maladaptive shifts in motivation, at least at the start of university studies. As a consequence, individual counseling appears to be a useful instrument for intervention in serious cases, but this seems to be inadequate to reach the broad majority of those affected by strong motivational decreases (Palmer \& Rodger, 2009). Beyond that, preventative measures appear to be called for in mitigating the general motivational slump. These could take place in the context of closer supervision on the part of academic advisers or tutors (see Bachmann et al., 1999; Scanlon, 2009; Walsh \& Carl, 2009), whereby university teachers should be provided with the skills needed to maintain and promote student motivation, or the implementation of decisive motivational training, either in the context of introductory courses or by means of computer-based approaches (e.g., Perry, Hall \& Ruthig, 2007).

\section{References}

Aiken, L. S., \& West, S. G. (1991). Multiple regression: Testing and interpreting interactions. Newbury Park, CA: Sage.

Bachmann, N., Berta, D., Eggli, P., \& Hornung, R. (1999). Macht Studieren krank? Die Bedeutung von Belastung und Ressourcen für die Gesundheit der Studierenden [The significance of stress and resources for university students' health]. Bern, Switzerland: Huber.

Baumert, J., Heyn, S., \& Köller, O. (1992). Das Kieler Lernstrategien-Inventar (KSI) [The Kiel Learning Strategy Inventory KSI]. Kiel, Germany: Leibnitz Institute for Science and Mathematics Education.

Chang, P. P. W., Cohen, L., Pike, L. T., Pooley, J. A., \& Breen, L. (2003). The Edith Cowan University School of Psychology Mentoring Programme: From reducing attrition to building learning communities. In F. Kochan, \& J. Pascarelle (Eds.), Global perspectives of the reconstruction of contexts, learning communities and cultures through mentoring (pp. 277-293). Greenwich, CT: Information Age Publishing.

Choi, N. (2005). Self-efficacy and self-concept as predictors of college students' academic performance. Psychology in the School, 42, 197-205. http://dx.doi.org/10.1002/pits.20048

Cohen, J. (1988). Statistical power analysis for the behavioral sciences. Hillsdale: Erlbaum.

Dresel, M. \& Hall, N. (2013). Motivation. In N. Hall \& T. Götz (Eds.), Emotion, motivation, and self-regulation: A handbook for teachers (pp. 57-122). Bingley, UK: Emerald.

Dresel, M., \& Haugwitz, M. (2005). The relationship between cognitive abilities and self-regulated learning: Evidence for interactions with academic self-concept and gender. High Ability Studies, 16, 201-218. http://dx.doi.org/10.1080/13598130600618066

Dweck, C. S. (1999). Self-theories. Their role in motivation, personality, and development. New York: Psychology Press.

Eccles, J. S., \& Wigfield, A. (2002). Motivational beliefs, values and goals. Annual Review of Psychology, 53, 109-132. http://dx.doi.org/10.1146/annurev.psych.53.100901.135153

Elliot, A. J., \& McGregor, H. A. (2001). A 2x2 achievement goal framework. Journal of Personality and Social 
Psychology, 80, 501-519. http://dx.doi.org/10.1037/0022-3514.80.3.501

Engeser, S., \& Rheinberg, F. (2008). Flow, performance and moderators of challenge-skill balance. Motivation and Emotion, 32, 158-172. http://dx.doi.org/10.1007/s11031-008-9102-4

Fischer, N., \& Rustemeyer, R. (2007). Motivationsentwicklung und schülerperzipiertes Lehrkraftverhalten im Mathematikunterricht [The impact of perceived teacher behaviour on motivational development in mathematics]. German Journal of Educational Psychology, 21, 135-144.

http://dx.doi.org/10.1024/1010-0652.21.2.135

Fryer, J. W., \& Elliot, A. J. (2007). Stability and change in achievement goals. Journal of Educational Psychology, 99, 700-714. http://dx.doi.org/10.1037/0022-0663.99.4.700

German Federal Ministry of Education and Research (2012). Studierende und Studienanfänger/-innen im 1. Hochschulsemester nach Fächergruppen, Hochschulart und Geschlecht [University freshman grouped by subject groups, type of higher education institution, and sex]. Retrieved from German Federal Ministry of Education and Research website: http://www.datenportal.bmbf.de/portal/index.html

Gold, A., \& Kloft, C. (1991). Der Studienabbruch: Eine Analyse von Bedingungen und Begrundungen [Dropout from university studies: An analysis of causes and reasons]. Zeitschrift für Entwicklungspsychologie und Pädagogische Psychologie, 23, 265-279.

Gold, A., \& Souvignier, E. (2005). Prognose der Studierfähigkeit: Ergebnisse aus Längsschnittanalysen [Prediction of college outcomes: Results from longitudinal studies]. Zeitschrift für Entwicklungspsychologie und Pädagogische Psychologie, 37, 214-222. http://dx.doi.org/10.1026/0049-8637.37.4.214

Heublein, U., Schmelzer, R., \& Sommer, D. (2008). Die Entwicklung der Studienabbruchquote an deutschen Hochschulen [Developments in drop-out rates at German universities]. Hannover, Germany: HIS.

House, J. D. (1992). The relationship between academic self-concept, achievement-related expectancies, and college attrition. Journal of College Student Development, 33, 5-10.

Maehr, M. L., \& Zusho, A. (2009). Achievement goal theory: The past, present, and future. In K. R. Wentzel, \& A. Wigfield (Eds.), Handbook of motivation at school (pp. 77-104). New York: Routledge.

Marsh, H. W. (1987). The big-fish-little-pond effect on academic self-concept. Journal of Educational Psychology, 79, 280-295. http://dx.doi.org/10.1037/0022-0663.79.3.280

Marsh, H. W., \& Craven, R. (1997). Academic self concept: Beyond the dustbowl. In G. D. Phye (Ed.), Handbook of classroom assessment (pp. 131-198). San Diego, CA: Academic Press.

Marsh, H. W., \& Martin, A. J. (2011). Academic self-concept and academic achievement: Relations and causal ordering. British Journal of Educational Psychology, 81, 59-77. http://dx.doi.org/10.1348/000709910X503501

Meier, A. M., Reindl, M., Grassinger, R., Berner, V. D., \& Dresel, M. (in press). Development of achievement goals across the transition out of secondary school International Journal of Educational Research.

Middleton, M. J., \& Midgley, C. (1997). Avoiding the demonstration of lack of ability: An underexplored aspect of goal theory. Journal of Educational Psychology, 89, 710-718.

http://dx.doi.org/10.1037/0022-0663.89.4.710

Midgley, C., Kaplan, A., \& Middleton, M. (2001). Performance-approach goals: Good for what, for whom, under what circumstances, and at what cost? Journal of Educational Psychology, 93, 77-86. http://dx.doi.org/10.1037/0022-0663.93.1.77

Moller, A. C. \& Elliot, A. J. (2006). The 2 x 2 achievement goal framework: An overview of empirical research. In A. Mittel (Ed.), Focus on educational psychology (pp. 307-326). New York: Nova Science.

Moschner, B. (2000). Selbstkonzept, Lernmotivation und Lernstrategien im Studienverlauf, [Self-concept, learning motivation, and learning strategies in course of undergraduate education]. In H. Metz-Goeckel \& B. Hannover (Eds.), Selbst, Motivation und Emotion: Dokumentation des 4. Dortmunder Symposiums für Pädagogische Psychologie [Self, motivation, and emotion: Documentation of the 4. Dortmund Symposium on Educational Psychologie] (pp. 33-43). Berlin, Germany: Logos.

Muis, K. R. \& Edwards, O. (2009). Examining the stability of achievement goal orientation. Contemporary Educational Psychology, 34, 265-277. http://dx.doi.org/10.1016/j.cedpsych.2009.06.003

Ning, H. K., \& Downing, K. (2010). The reciprocal relationship between motivation and self-regulation: A 
longitudinal study on academic performance. Learning and Individual Differences, 20, 682-686. http://dx.doi.org/10.1016/j.lindif.2010.09.010

Olani, A. (2010). Predicting first year students' academic success. Electronic Journal of Research in Educational Psychology, 7, 1053-1072.

Retrieved from: http://investigacion-psicopedagogica.org/revista/new/english/index.php

Palmer, A., \& Rodger, S. (2009). Mindfulness, stress, and coping among university students. Canadian Journal of Counselling, 43, 198-212.

Perry, R. P., Hall, N. C., \& Ruthig, J. C. (2007). Perceived (academic) control and scholastic attainment in higher education. In R. P. Perry, \& J. C. Smart (Eds.), The scholarship of teaching and learning in higher education: An evidence-based perspective (pp. 477-551). Dordrecht, Netherlands: Springer.

Peugh, J. L., \& Enders, C. K. (2004). Missing Data in Educational Research: A Review of Reporting Practices and Suggestions for Improvement. Review of Educational Research, 74, 525-556. http://dx.doi.org/10.3102/00346543074004525

Phan, H. P. (2010). Empirical model and analysis of mastery and performance-approach goals: A developmental approach. Educational Psychology, 30, 547-564. http://dx.doi.org/10.1080/01443410.2010.491936

Pillay, A. L., \& Ngcobo, H. S. B. (2010). Sources of stress and support among rural-based first-year university students: An exploratory study. South African Journal of Psychology, 40, 234-240. http://dx.doi.org/10.1177/008124631004000302

Pintrich, P. R., \& Zusho, A. (2007). Student motivation and self-regulated learning in the college classroom. In R. P. Perry, \& J. C. Smart (Eds.), The scholarship of teaching and learning in higher education: An evidence-based perspective (pp. 731-810). Dordrecht, Netherlands: Springer.

Robbins, S. B., Lauver, K., Le, H., Davis, D., Langley, R., \& Carlstrom, A. (2004). Do psychological and study skill factors predict college outcome? Psychological Bulletin, 130, 261-288. http://dx.doi.org/10.1037/0033-2909.130.2.261

Scanlon, L. (2009). Metaphors and mentoring: Constructing a mentor typology from the perspective of student mentors. International Journal of Evidence Based Coaching and Mentoring, 7, 71-81.

Schiefele, U., Streblow, L., \& Brinkmann, J. (2007). Aussteigen oder Durchhalten. Was unterscheidet Studienabbrecher von anderen Studierenden? [Dropping out or persevering: What distinguishes university dropouts from other students?]. Zeitschrift für Entwicklungspsychologie und Pädagogische Psychologie, 39, 127-140. http://dx.doi.org/10.1026/0049-8637.39.3.127

Schiefele, U., Streblow, L., Ermgassen U., \& Moschner, B. (2003). Lernmotivation und Lernstrategien als Bedingungen der Studienleistung. Ergebnisse einer Längsschnittstudie [The Influence of Learning Motivation and Learning Strategies on College Achievement: Results of a Longitudinal Analysis]. German Journal of Educational Psychology, 17, 185-198. http://dx.doi.org/10.1024//1010-0652.17.34.185

Schunk, D. H., Pintrich, P. R., \& Meece, J. L. (2007). Motivation in Education: Theory, Research and Application (3rd ed.). Englewood Cliffs, NJ: Prentice Hall.

Skaalvik, S., \& Skaalvik, E. M. (2005). Self-concept, motivational orientation, and help-seeking behavior in Mathematics: A study of adults returning to High School. Social Psychology of Education. 8, 285-302. http://dx.doi.org/10.1007/s11218-005-3276-3

Spinath, B., \& Spinath, F. M. (2005). Longitudinal analysis of the link between learning motivation and competence beliefs among elementary school children. Learning and Instruction, 15, 87-102. http://dx.doi.org/10.1016/j.learninstruc.2005.04.008

Valentine, J. C., DuBois, D. L., \& Cooper, H. (2004). The relations between self-beliefs and academic achievement: A systematic review. Educational Psychologist, 39, 111-133. http://dx.doi.org/10.1207/s15326985ep3902_3

Walsh, C., \& Carl, P. D. (2009). Academic tutors at the frontline of student support in a cohort of students succeeding in higher education. Educational Studies, 35, 405-424. http://dx.doi.org/10.1080/03055690902876438

Wigfield, A., \& Eccles, J. (1992). The development of achievement task values: A theoretical analysis. Developmental Review, 12, 265-310. http://dx.doi.org/10.1016/0273-2297(92)90011-P 
Wigfield, A., \& Eccles, J. S. (Eds.). (2002). Development of achievement motivation. San Diego, CA: Academic Press.

Wigfield, A., Tonks, S., \& Klauda, S. L. (2009). Expectancy-value theory. In K. R. Wenzel, \& A. Wigfield (Eds.), Handbook of motivation at school (pp. 55-75). New York: Routledge.

Ziegler, A., Dresel, M., Schober, B., \& Stoeger, H. (2005). Ulm Motivational Test Battery (UMTB): Documentation of items and scales (Ulm educational psychological research report, No. 15). Ulm, Germany: Ulm University, Department of Educational Psychology.

Ziegler, A., Dresel, M., \& Stoeger, H. (2008). Addressees of performance goals. Journal of Educational Psychology, 100, 643-654. http://dx.doi.org/10.1037/0022-0663.100.3.643

\section{Appendix}

Scale to assess the intention to terminate university studies or switch majors (negative items are marked with an asterisk, original German items in brackets)

(1) I often think about dropping out of my current course of studies or changing my major. [Ich denke häufig darüber nach, mein derzeitiges Studium abzubrechen oder den Studiengang zu wechseln.]

(2) I am sure that I will be able to complete my current course of studies.* [Ich bin mir sicher, dass ich mein derzeitiges Studium zu Ende bringen kann.]

(3) The thought often crosses my mind that my current course of studies is not for me. [Mir kommt häufig der Gedanke, dass mein derzeitiger Studiengang nichts für mich ist.]

(4) I am on the verge of dropping out of my current course of studies or changing my major. [Ich bin kurz davor, mein derzeitiges Studium abzubrechen oder den Studiengang zu wechseln.]

(5) I am sure that my current course of studies is the right one for me.* [Ich bin mir sicher, dass mein derzeitiges Studium das Richtige für mich ist.]

\section{(c)) EY}

This work is licensed under a Creative Commons Attribution 3.0 License. 